\title{
LIGHTER HIGH STRENGTH CONCRETE BEAM
}

\author{
Nuri Mohamed Elbasha \\ Department of Civil Engineering, Sabratha University, Libya \\ E-mail: elbashaaustralia@yahoo.com.au
}

\begin{abstract}
High strength concrete (HSC) has been used extensively in civil construction projects worldwide because it reduces the cross section and the weight of long construction members. In recent years a marked increase in the use of High Strength Concrete (HSC) has been evident in Australian building construction despite the fact that the current Australian design standard provides no design rules for such a material. Very limited information on the properties of HSC and its design and construction processes are available in Australia, although in recent times many studies have been undertaken to produce material and, more importantly, to determine its characteristic. In the last 20 years there has been extensive research to economically utilize new components to improve the quality of HSC. HSC produces smaller but stronger structural elements with large spaces available. It has been studied that the cost of using HSC instead of Normal Strength Concerete (NSC) in different types of constructions. This proved that structures constructed with HSC are lighter and economical compared with those constructed with NSC. In the long term durability significantly affects project costs. In other words after several years a concrete structure needs rehabilitation or in critical cases must be demolished, therefore the price of a project consists of initial costs plus those covering any rehabilitation. A huge amount of money could be saved by utilizing the durability characteristics of high strength concrete. This study presents recent information and the benefits of high strength concrete. Also, provides in brief an experimental proof that installing a helix with a suitable pitch and diameter in the compression zone of beams significantly enhances their strength and ductility. Therefore, designers could confidently use high-strength concrete and helical confinement to design long and light reinforced concrete beams.
\end{abstract}

Keywords: Long and Light Reinforced Concrete Beams; High Strength Concrete; Helical Confinement.

\section{Introduction}

High strength concrete is defined as a concrete having a greater compressive strength than normal strength concrete. However, this definition is changing from country to another and from time to time. For example, "high strength concrete is defined by FIP/CEB as concrete with a cylinder strength above $60 \mathrm{MPa}$ " (Helland, 1995) but the ACI318 definition of HSC is a 
concrete with a cylinder strength above $42 \mathrm{MPa}$ (ACI 318-02, 2002). The Australian standard classifies high strength concrete as having a cylinder strength above $65 \mathrm{MPa}$ (AS3600, 2001). There is a belief that taking the strength as an indicator of high strength concrete is more reliable than its performance (high performance concrete) because measuring performance is very difficult compared to measuring strength. However, the title high strength concrete is not an indicator of its strength only but also of its high quality and durability. Therefore, this research uses the term high strength rather than high performance concrete. Aggregate, cement, and water are the main materials of normal strength and high strength concrete. However, the difference between these materials for normal and high strength concrete is adding water reduction admixture and their quality and ratio.

It is generally accepted that helix confinement increases the strength and ductility of confined concrete better than rectangular ties. Helical reinforcement increases the ductility and compressive strength of concrete under compression by resisting lateral expansion due to Poisson's effect. In this study helical reinforcement is used in the compression zone of overreinforced high strength concrete beams. The effectiveness of helical confinement depends on variables such as helical pitch and diameter.

\section{Economics of HSC}

High strength concrete with a compressive strength of $100 \mathrm{MPa}$ is used widely in high rise buildings and bridges. In France concrete with a strength up to $800 \mathrm{MPa}$ is produced for special applications (Nawy, 2001). In the last 20 years there has been extensive research to economically utilise new components to improve the quality of HSC. HSC produces smaller but stronger structural elements with large spaces available. There are several publications to study the cost of using HSC instead of NSC in different types of constructions. For example, Schmidt and Hoffman found that the cost of elements made from $41 \mathrm{MPa}$ compressive strength concrete is reduced when $62 \mathrm{MPa}$ compressive strength concrete was used (Schmidt and Hoffman, 1975). This proved that structures constructed with HSC are more economical than those constructed with NSC.

In the long term durability significantly affects project costs. In other words, after several years a concrete structure needs rehabilitation or in critical cases must be demolished, therefore the price of a project consists of initial costs plus those covering any rehabilitation. A huge amount of money could be saved by utilising the durability characteristics of high strength concrete. Haug stated that most platforms have been designed with a service life of approximately 30 years but projects constructed with high strength concrete have a service life of approximately 70 years (Haug, 1994). Thornton et al. stated that using high strength concrete of $80 \mathrm{MPa}$ reduces the size of the elements, saves rentable space, which makes the project economical (Thornton et al, 1994). 
High strength concrete has characteristics that cannot be found in normal concrete. A huge volume of concrete is produced in the world every year to construct bridges, high rise structures, and waste water treatment plants. However, the costs of rehabilitation and replacing are very high, for example in the United States about \$500 billion is re needed just to replace existing bridges and highways (Nawy, 2001). There is a need to reduce construction or rehabilitation costs through utilising the new technology of high strength concrete.

\section{Main Factors Affecting the Cost of HSC}

\section{Research and Development}

Research on high strength concrete has been under way for many years in many countries. However, HSC is the most prestigious subject for research at the international level. Researchers aim to find ways of maximising performance over the long term while minimising the cost. Continuous funding for research is important to gain new information and develop new technology to produce the best quality HSC and reduce the cost. The characteristics of HSC differ from normal strength concrete because of the different materials used to make them. Thus, the stress-strain diagram for normal strength is parabolic but linear for HSC, up to failure. This difference may cause differences in design parameters especially those related to the stress-strain relationship. However, estimating the cost is affected by the differences in the design methods of HSC and NSC although there is no evidence so far which suggests there is a major difference in design factors between them. Nawy stated that "No conclusive evidence exists at this time on the need for major changes in the provisions of the ACI 318 code parameters for design of very high strength concrete structures, that is concrete with compressive strength exceeding $83 \mathrm{MPa"} \mathrm{(Nawy,2001).} \mathrm{However,} \mathrm{there} \mathrm{is} \mathrm{a} \mathrm{strong} \mathrm{need}$ for research to study the properties of high strength concrete structure. The use of HSC with longitudinal and lateral reinforcement improves mechanical qualities, fire resistance, the ductility of reinforced concrete components, flexibility and cracking, the dynamic behaviour of structures, and shock resistance (Malier and Richard, 1995). However ongoing research into the design structure of HSC may reduce the cost of the raw materials through more efficient design methods.

\section{Type and Location of the Structure}

The cost is affected by its location, and whether the concrete is required to resist temperature changes and the deleterious effect of chemicals and acid rain. The cost is also affected by the type of structure, eg, nuclear, and its location, eg, under water. Thus, the type of concrete depends on the cost of its placement and finishing and any other special requirements. 


\section{Design Mixture}

HSC quality depends on the quality and percentage of materials used. Quality could be controlled through a quality control programme by testing samples in lab and field. The cost of material is affected by demands for the material and the cost of transportation.

\section{Quality Control}

HSC is a material whose properties such as compressive strength and tensile strength are difficult to predict. The mix must be designed to have an average compressive strength greater than the required value of its compressive strength. HSC needs a large number of control tests compared to NSC which should be done by professional teams with experience, which will eventually increase the cost. Full scale laboratory and training for HSC has not reached the required level which can cause an unacceptable number of problems in handling delicate qualities of HSC to the market (ACI Committee 363R, 1992). On the other hand, the number of clients and competition between suppliers reduces the cost.

\section{Advantages of Using HSC}

It has been proven that HSC can carry a compressive load at a lower cost than NSC (Schmidt and Hoffman, 1975). However, the advantages of HSC more than compensate for the increased costs of raw materials and quality control. The following are the main advantages of high strength concrete (Schmidt and Hoffman, 1975; Chan and Anson 1994).

1. It satisfies the need for a high modulus of elasticity.

2. It reduces member size which leads to:

a) increasing rentable space.

b) reducing the formwork light.

c) reducing the volume of concrete (Lighter).

d) reducing construction time.

e) reducing labour.

f) reducing the dead load reduces the size of the foundation plus gaining the previous benefits from $b$ to $e$.

3. Saving in high rise building; by saving in one storey multiplied by the number of stories.

4. Using HSC reduces the number of beams which increases their span.

5. Using HSC reduces the number of columns and foundations.

6. Higher resistance to freezing, thawing, and chemical attack.

7. Reduced maintenance and repair costs.

8. Early removal of formwork and an avoidance of re-shoring. 


\section{Concrete Confinement}

The confinement of concrete in compression is a complicated phenomenon, but there is a continuing effort to understand its behaviour through extensive international experimental programmes. Confinement is either, active or passive confinement. Active confinement occurs when concrete is subjected to pressure such as a confining fluid, while passive confinement occurs when lateral reinforcement applies a confining reaction towards the concrete. As a result of this compressive load, confined concrete will expand but the confinement resists expansion due to passive confining pressure, thus lateral reinforcement is called passive confinement. The confining pressure is affected by several factors such as the spacing and yield strength of the confining reinforcement.

This paper focuses only on passive confinement where concrete is confined by transverse reinforcement via a helix. Concrete expands laterally under a compressive load but the confinement will resist concrete expansion and then reduce the tendency for internal cracking, which significantly enhances the strength and ductility. Brittle compression failure can be avoided by using proper confinement, which restrains lateral expansion and increases ductility and strength of concrete. Most of the studies about confinement of concrete in the compression zone in beams is based on the results of research on columns, as the idea of a confined compression zone in beams has only been developed recently. Based on this, more study and data on the behaviour of confined HSC beams is needed. Elbasha showed through experimental testing that helical confinement enhances the strength and ductility of beams with high strength concrete (Elbasha, 2005).

As mentioned above, the confining reinforcement increases ductility and compressive strength of concrete under compression by resisting lateral expansion due to Poisson's effect upon loading. The behaviour of confined concrete depends on the effectiveness of the confinement, which in turn is affected by several important variables such as helical pitch, helix yield strength and helix bar diameter. There is no confining effect after loading, until a particular lateral stress due to Poisson's effect is reached and then the confinement commences. Confinement does not increase strength or ductility initially, but when the axial stress is about $60 \%$ of the maximum cylinder strength, the concrete is effectively confined (Sargin, 1971; Martinez et al., 1984). However, there is no additional confinement effect if the confining steel reaches its yield strength.

\section{Confined Concrete Compressive Strength}

The strength of concrete increases significantly under triaxial compression but lateral pressure counteracts its tendency to expand laterally, which increases its strength.

The concept of beam confinement is not fully understood because of limited research on this topic, although interest is gradually increasing. The availability of high strength materials such 
as high strength steel and high strength concrete enhances the strength of reinforced concrete columns as well as beams, but increasing strength decreases beam ductility. Installing confining reinforcement in the compression zone of a reinforced concrete beam enhances it's ductility and compressive strength.

Many researchers have developed theories and models based on experimental results to study the behaviour of confined columns, but only limited theories and models have been developed to study confined beams. It is not possible to predict the behaviour of confined beams using the confined column models because the loading conditions are different and the column confinement reinforcement is usually placed throughout the column, whereas in beams, this is not likely to be the case. A great deal of experimental work is needed to predict the behaviour of a helically confined beam.

Extensive investigation was carried out on full scale beams to study how different variables affected the behaviour of over-reinforced HSC helically confined beams. Twenty beams 4000 $\mathrm{mm}$ long by $200 \mathrm{~mm}$ wide by $300 \mathrm{~mm}$ deep, with $3600 \mathrm{~mm}$ clear span were subjected to four point loading, with an emphasis placed on midspan deflection. A helix confinement was installed at the compression zone, where the outside diameter of confined core was kept consistent at $160 \mathrm{~mm}$ for all beams. The concrete cover was kept consistent at $20 \mathrm{~mm}$ for all beams. The position of helices in beams affects confinement, the spalling off phenomena, and the confined strain developed from resisting the concrete expansion. Figure 1 shows Fixing the helical reinforcement in the compression zone of a reinforced concrete beam. Also, shows the lateral forces are restrained by helix confinement in the compression zone of a reinforced concrete beam.

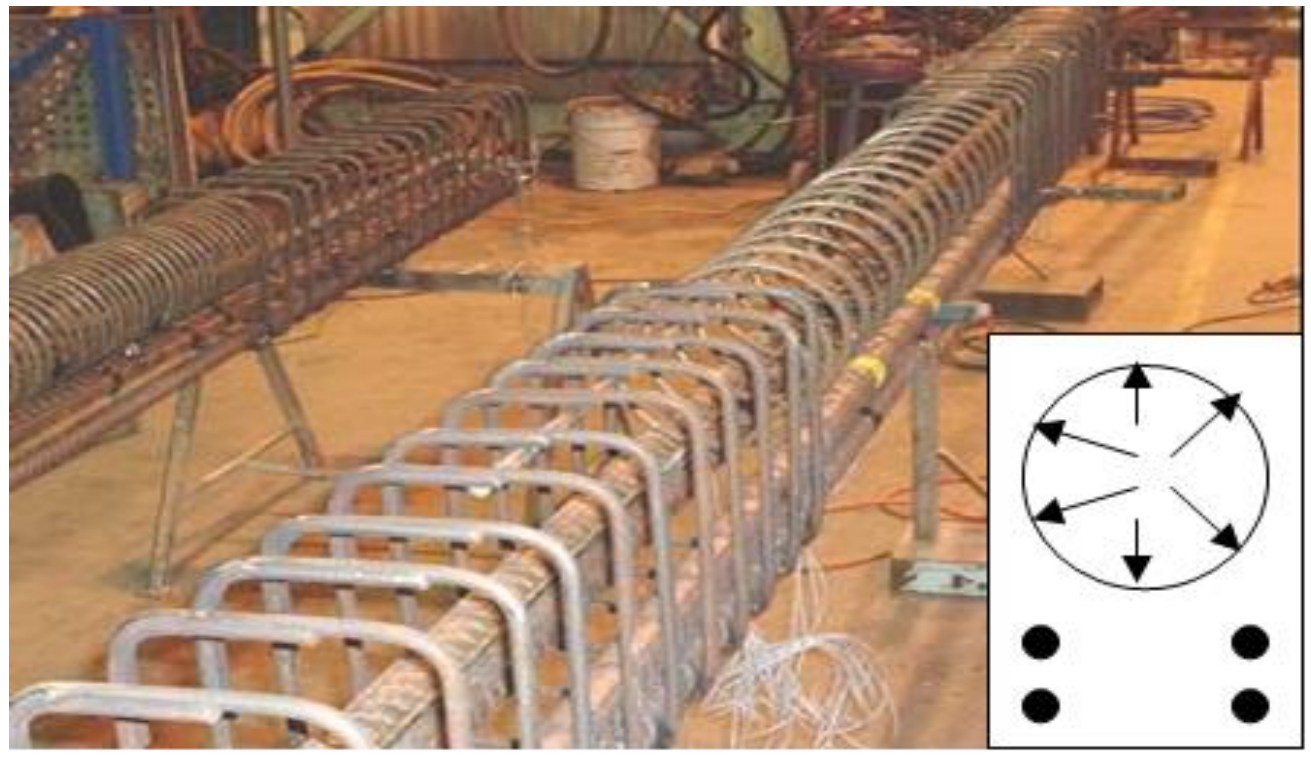

Figure (1): Fixing the Helical Reinforcement in The Compression Zone of a Reinforced Concrete Beam 
A high strength concrete between $72 \mathrm{MPa}$ and $105 \mathrm{MPa}$ was used to construct the 20 beams. The concrete cylinders were tested on the same day as the beam test to determine the actual strength of concrete.

The most important conclusions drawn from both the experimental and analytical parts were that, using steel helices to encase concrete in the compression zone increases ductility and improves overall performance of HSC beams. The experimental testing conducted proved that using helices to enhance the characteristics of high strength concrete beams is an effective technique.

High strength concrete and high strength steel have benefits for different structures such as high rise structures and larger span girders but these materials lack ductility. The experimental results proved that helical confinement in the compression zone of beams enhances the strength and the ductility of over-reinforced HSC beams. However, as development in material science and computational technology is somewhat unimaginable, it is believed that overreinforced helically confined HSC beams will become a very important design concept for safeguarding structures.

Helical confinement will restrain transverse stress in concrete under compression, and delay compression failure which allows the longitudinal reinforcement to yield before the confined concrete fails. The interval between the longitudinal steel yielding and failure depends on the characteristics of helical confinement especially helical pitch. Figure 2 shows the Ultimate deflection of High Strength Concrete Beam and Figure 3 shows the confined concrete core of one of the tested beams.

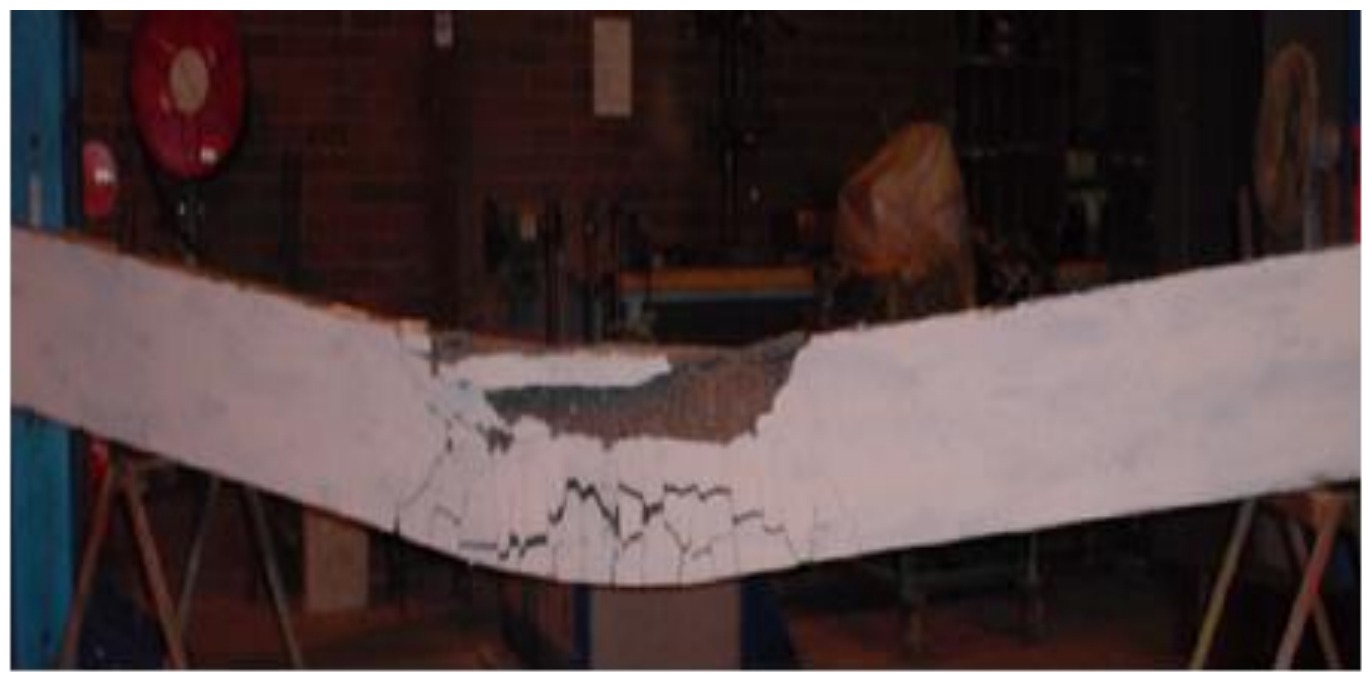

Figure (2): Ultimate Deflection of High Strength Concrete Beam 


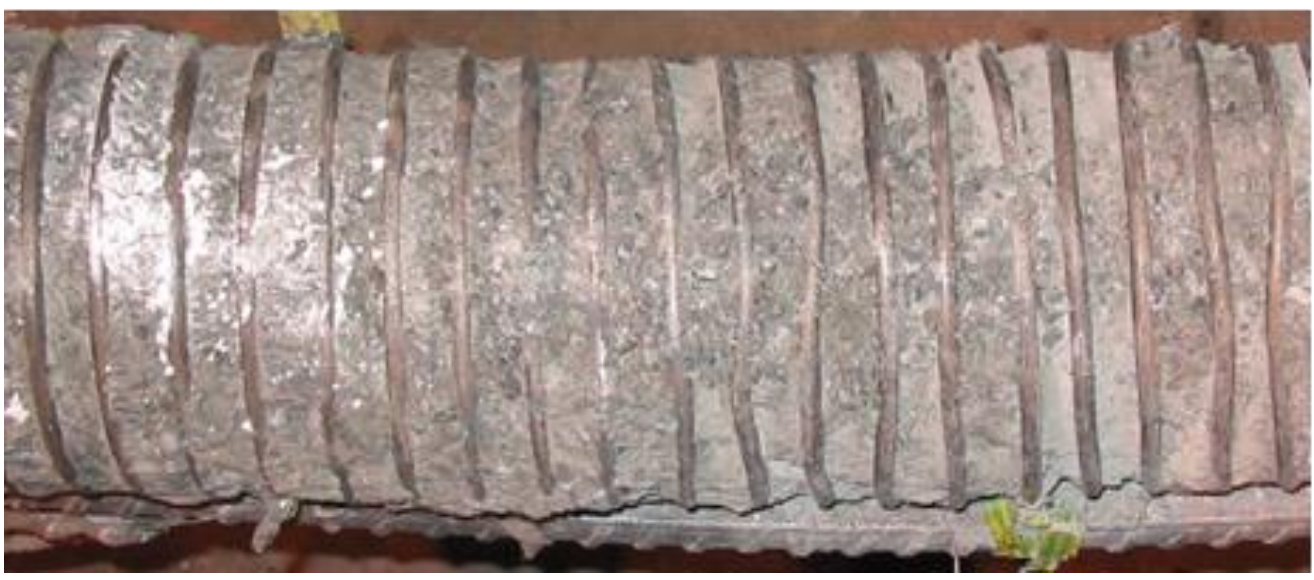

Figure (3): The Confined Concrete Core of One of The Beams

When there is helical confinement in the compression zone of an over-reinforced concrete beam, it fails in a ductile manner. Therefore, when the strength and/or ductility of a beam must be increased, helical confinement can be added into the compression area. In these instances the tensile reinforcement can be increased above the maximum ratio of longitudinal reinforcement imposed by design standards such as (AS3600, 2001). The concept behind this is that longitudinal reinforcement significantly affects the behaviour of under-reinforced concrete beams while the characteristics of helical confinement have a major effect on overreinforced helically confined HSC beams

Within the range used in the test, helical pitch has a greater effect on over-reinforced HSC helically confined beams than helical diameter, helical yield strength and concrete compressive strength. This significant influence of helical pitch on the behaviour of overreinforced HSC helically confined beams encourages using it as an important parameter in design equations.

\section{Conclusions}

The primary long and short term advantages of high strength concrete are, low creep and shrinkage, higher stiffness, higher elastic modulus, higher tensile strength, higher durability (resistance to chemical attacks) and higher shear resistance. In addition, high strength concrete reduces the size of the member, which in turn reduces the form size, concrete volume, construction time, labour costs and dead load. Reducing the dead load reduces the number and size of the beams, columns and foundations. Thus, there is a positive impact on reduction of maintenance and repair costs and an increase in rentable space. Other, yet to be discovered advantages may also exist. High strength concrete has definite advantages over normal strength concrete. The lack of ductility of HSC is a definite concern. 
It is important that reinforced concrete members are able to withstand large deformations whilst maintaining strength capacity in situations where there is a need to withstand significant overloads. Here is where HSC comes into its own. If adequately confined, a greater load carrying capacity can be achieved, and along with properties such as higher elastic modulus, higher resistance to physical and chemical deteriorations and the early stripping of formwork all make this material's use very advantageous.

This paper has shown that helical confinement in the compression zone of beams enhances the strength and the ductility of over-reinforced HSC beams. However, as development in material science and computational technology is somewhat unimaginable, it is believed that helically confined HSC beams will become a very important design concept for safeguarding light structures. Finally, Lighter High Strength Concrete Beam could be made by using the high strength concrete (HSC) and helical confinement.

\section{References}

- Helland, S. (1995). "Application of High Strength Concrete in Norway." proceeding, ACI International Conference on High An International Perspective, Montreal, ed. J. A. Bickley, ACI SP-167, American Concrete Institute, 27-53.

- ACI 318-02. Building Code Requirements for Structural Concrete. American Concrete Institute, Michigan, 2002.

- AS3600. Australian Standard for Concrete Structures. Standards Association of Australia. North Sydney, 2001.

- Nawy, E. G. (2001). "Fundamentals of High-Performance Concrete." Second edition. John Wiley \& Sons, Canada.

- Schmidt, W. and Hoffman, E. S. (1975). "Nine Thousand-Psi." Civil Engineering Magazine, 45(5), 52-55.

- Haug, A. K. (1994). "Concrete Technology, the Key to Current Concrete Platform Concepts." proceeding, ACI International Conference on High performance Concrete, Singapore, ed. V.M. Malhotra, ACI SP-149, American Concrete Institute, 63-80.

- Thornton, C. T., Mohamad, H., Hungspruke, U. and Joseph, L. (1994). "High Strength Concrete for High-Rise Towers." proceeding, ACI International Conference on High Performance Concrete, Singapore, ed. V.M. Malhotra, ACI SP-149, American Concrete Institute, 769-784.

- Malier, Y. and Richard, P. (1995). "High Performance Concrete- Custom Designed Concrete: A Review Of The French Experience and Prospects For Future Development." proceeding, 
ACI International Conference on High An International Perspective, Montreal, ed. J. A. Bickley, ACI SP-167, American Concrete Institute, 55-80.

- ACI Committee 363R-State of Art Report on High-Strength Concrete "State of the Art Report on High-Strength Concrete”, American Concrete Institute, Detroit, 1992.

- Chan, S. Y. N. and Anson, M. (1994). "The Ultimate Strength and Deformation of Plastic Hinges in Reinforced Concrete Frameworks." Magazine of Concrete Research, 46(169), 235 236.

- Elbasha, N. M. (2005). "Behaviour of Over Reinforced HSC Helically Confined." Ph. D thesis, School of Civil, Mining and Environmental Engineering, The University of Wollongong, Wollongong, Australia.

- Sargin, M. (1971). "Stress-Strain Relationships for Concrete and the Analysis of Structural Concrete Sections.” Solid Mechanics Division Study No 4, university of Waterloo, 167pp.

- Martinez, S. Nilson, A. H. and Slate, F. O. (1984). "Spirally Reinforced High-Strength Concrete Columns.” ACI Structural Journal, 81(5), 431-442. 